\title{
Competency Assessment and Factors Associated with It among Health Professionals at Debre Birhan Health Science College
}

\author{
Awraris Hailu1 ${ }^{*}$, Henok Ditta1 ${ }^{1}$, Zebideru Zewdie ${ }^{2}$ \\ ${ }^{1}$ Debre Birehan Health Science College, Debre Birhan, Ethiopia \\ ${ }^{2}$ Amhara Regional Health Bureau, Bahr Dar, Ethiopia \\ Email: *awrarishailu@yahoo.com, awrarishailu@gmail.com, henok.ditta@yahoo.com
}

Received 14 March 2014; revised 18 May 2014; accepted 5 June 2014

Copyright (C) 2014 by authors and Scientific Research Publishing Inc.

This work is licensed under the Creative Commons Attribution International License (CC BY). http://creativecommons.org/licenses/by/4.0/

(c) (i) Open Access

\begin{abstract}
Background: Competency assessment has a key role in the assurance of quality professionals in every discipline. Competency assessment is a method by which we can verify that our employees are competent to perform tasks timely. To derive the greatest benefit from the application of competency assessment in the health professionals, we must be sure that we are addressing areas where our efforts are utilized to optimize the patient care. There is no research done on the competency assessment so far except the report send by Technical Vocational and Educational Training. Objectives: To assess knowledge, attitude and practice of health professionals towards competency assessment and factors were associated with competencies at Debre Birhan Health Science College, 2013. Methods: A facility based cross sectional study was conducted using interview technique. Study participants were all students taking competency assessment in all departments at Debre Berhan Health Science College in two rounds. The percentage of participants who were competent was computed. Factors associated with competency were assessed using bivariate and multivariable logistic regression. Results: Among the total participants $(n=287)$, (57.8 percent) were female. Among the $(n=287)$ study participants, $226(78.7 \%)$ were competent. Of these, $\mathbf{8 8 . 5 \%}$ of the candidates were learned at governmental institution. Predictors of competency were department of the respondent AOR [95\%]; $0.05[0.01,0.45]$, expectation of the results [AOR $(95 \% \mathrm{CI})=0.13(0.02,0.85)]$, number of competency taken $[\mathrm{AOR}(95 \% \mathrm{CI})=0.11(0.01,0.88)]$ and candidates' knowledge of their right and obligations AOR [95\%]; 3.7 [1.3, 10.3]. Conclusions: Significant numbers of candidates were not yet competent due to various factors at different level. Therefore, comprehensive work should be done on the instructors, students and the center to make the candidates competent.
\end{abstract}

${ }^{*}$ Corresponding author.

How to cite this paper: Hailu, A., et al. (2014) Competency Assessment and Factors Associated with It among Health Professionals at Debre Birhan Health Science College. Open Journal of Nursing, 4, 493-500.

http://dx.doi.org/10.4236/ojn.2014.47052 


\section{Keywords}

\section{Competency, Quality Education, College, Health Professionals}

\section{Introduction}

As you know, the importance of competency assessment to the input of qualified, productive and skilled professionals is unquestionable. Competency assessment Center was established since 2001 E.C to accomplish such jobs. The Amhara Regional Competency assessment Center was established on 2001 E.C. During 5 years of stay, the center has developed many inputs to the region. The center also analyzes the results of the assessed participants (candidates) and sends the feedback to the respective assessment centers.

According to the 2005 E.C Amhara Regional Competency assessment Center reports, a total of 23,291 governmental and private non-health professionals were assessed. 16,403 (70.43\%) were competent. Regarding the health professionals, about 2954 were assessed and only 10,369 (35.07\%) were competent [1].

When we see the achievement of the competency result with the candidates who attended the institution, of the 17,315 governmental non-health professionals, candidates 12,215 (70.5\%) were competent. A total of 5976 non-health professional participants attended private colleges and 4188 (70.1\%) were competent [1].

Regarding to the result of the health professionals, 778 governmental and 2176 private candidates were assessed and 437 (56.2\%), 599 (27.5\%) were competent respectively.

According to the 2005 E.C Amhara region competency assessment, the results of both the private and governmental institution candidates were almost similar. But with regard to the result of health professionals' assessment, the achievement was low. When we compared it with each other, the achievement of the private institution for the competency was relatively very low [1].

Competencies are a combination of several factors like motives, traits, self-concepts, attitudes or values, skills and abilities. All of them can differentiate superior performers from average performers. Since competencies take a composite view of an employee's ability to perform, they go beyond mere job knowledge. This becomes particularly useful when the definition of jobs itself changes under external competitive pressures [2]. Assessments of knowledge, decision making, performance and personal attributes, as well as integrated practice-based skills and tasks are described and compared on the basis of their validity, feasibility and practicality, fidelity, and relevance at difference stages of the professional development. It is acknowledged that no single assessment can evaluate all competencies and that assessments can be combined in complementary ways [3].

Today's industries place challenging demands on individuals, who are confronted with complexity in many parts of their activities. Defining such competencies can improve assessments of how well-prepared young employees and adults are for industries' challenges, as well as identify overarching goals for efficient operations and the lifelong learning. The set of competencies provides managements and staffs with a common understanding of the skills and behavior that are important to the organization. Therefore, it plays a key role in decisions for selection and recruitment of new employees, succession planning, career development, job rotation and transfer, project specific team development, performance measurement and training needs assessment [2].

\section{Literature Review}

Office of personal management (OPM) defines a competency as "A measurable pattern of knowledge, skills, abilities, behaviors, and other characteristics that an individual needs to perform work roles or occupational functions successfully." Competencies specify the "how" of performing job tasks, or what the person needs to do the job successfully. Competencies represent a whole-person approach to assessing individuals [4].

Competencies tend to be either general or technical. General competencies reflect the cognitive and social capabilities (e.g., problem solving, interpersonal skills) required for job performance in a variety of occupations. On the other hand, technical competencies are more specific as they are tailored to the particular knowledge and skill requirements necessary for a specific job. OPM has conducted a number of occupational studies to identify competencies for many Federal occupations [5]. When applicants participate in an assessment process, they are not the only ones being evaluated; the agency is being evaluated as well [5].

Assessment center exercises include, but are not limited to, job knowledge tests, personality tests, and struc- 
tured interviews. Applicant performance is usually observed and evaluated by multiple assessors (i.e., raters) [5].

\section{Factors That Makes Participant Competent/Not Yet Competent}

The keynote address outlines five major areas for research: assessment of professional competency, program effectiveness, effectiveness of instructional strategies, social context, and institutional change [6].

Related to the assessment tool, one must consider a number of important factors such as: 1) reliability; 2) validity; 3) technology; 4) the legal context; and 5) face validity/applicant reactions [5].

Reliability: Assessment reliability is demonstrated by the consistency of scores obtained when the same applicants are reexamined with the same or equivalent form of an assessment (e.g., a test of key boarding skills).

Validity: refers to the relationship between performance on an assessment and performance on the job.

There are different types of validity evidence. Which type is most appropriate will depend on how the assessment method is used in making an employment decision. For example, if a work sample test is designed to mimic the actual tasks performed on the job, then a content validity approach may be needed to establish the content of the test matches in a convincing way the content of the job, as identified by a job analysis. If a personality test is intended to forecast the job success of applicants for a customer service position, then evidence of predictive validity may be needed to show scores on the personality test are related to subsequent performance on the job. The most commonly used measure of predictive validity. When multiple selection tools are used, you can consider the combined validity of the tools.

Technology: The technology available is another factor in determining the appropriate assessment tool.

Face Validity/Applicant Reactions: Applicants who complete an assessment process leave with impressions about the face validity and overall fairness of the assessment procedure.

Work Samples and Simulations: Work sample tests require applicants to perform tasks or work activities that mirror the tasks employees perform on the job. Because work samples require applicants to perform tasks identical or highly similar to tasks from the job, great care is taken in trying to mimic the work environment to the greatest extent possible.

Structured Interviews: The level of structure in an interview can vary according to the constraints placed on the questions asked and evaluation criteria. Interviews also vary according to the specific competencies being measured.

Job Knowledge Tests: Job knowledge tests, sometimes referred to as achievement or mastery tests, typically consist of questions designed to assess technical or professional expertise in specific knowledge areas. Job knowledge tests evaluate what a person knows at the time of taking the test. Unlike cognitive ability tests, there is no attempt to assess the applicant's learning potential [5].

Utilizing a structured, competency-based approach to reference checking can increase the predictive validity of ratings in much the same way as structuring the employment interview process. A structured job analysis was used to identify the core job-related competencies deemed essential to effective performance in a family of customer-contact jobs within a 10,000-employee service organization. These competencies (Commitment, Teamwork, and Customer Service) were incorporated into a structured reference form and contacts were asked to rate applicants on a number of behavioral indicators within each competency. A structured telephone interview with contacts was then used to obtain evidence of actual occurrences to support the ratings. Results indicated using a structured telephone reference check increased the employer's ability to predict future job performance. Results also indicated a shorter contact-applicant relationship does not undermine predictions of future job performance [7].

\section{Methods}

A cross-sectional study was conducted to assess Knowledge, attitude and Practice towards competency assessment and factors associated with competency at Debre Berhan Health Science College in 2013. Debre Birhan Health Sciences College is located in North Shoa Zone, 695km from the capital city of the Amhara Region and $130 \mathrm{~km}$ from the capital of Ethiopia, Addis Ababa.

There are 31 academic staffs and 39 administrative staffs in the college. The health science college has been selected to be a center for competency assessment since 2001 E.C. Currently the college was providing assessment on pharmacy, clinical nurse, midwifery and health extension. Besides being a center for competency assessment the college is providing training depending on the demand of the region. Debre Birhan Health Sciences 
College had 520 (139 male and 381 female) students.

A total sample size of 270 was estimated after fixing proportion of Competency to be 20\% Amhara 2004 COC results, $95 \%$ CI, margin of error at $5 \%$ and none of response rate at $10 \%$. During the study time the remaining 17 candidates were included and the total sample size will be all 287 candidates.

Data were collected using structured interview questionnaires prepared in the national language (Amharic). Appropriateness of the questionnaires was checked by conducting pretest on $5 \%$ of the sample. Students who took competency assessment were asked to be interviewed in the separate rooms. Interview was conducted to the students who consented to participate in the study. The aim of the study was briefly explained for the study participants. Data collection was facilitated by trained data collectors. Permission to conduct this study was obtained from Debre Birhan Health Sciences College Research Committee. Data were collected after securing informed consent.

The collected data were entered, cleaned by EPI-info and analyzed using SPSS version 18. Socio economic/ demographic characteristics of the study participants and magnitude of competency were analyzed using frequency distribution. Competency was defined as the following: Competent-Participants became successful in both theory and practice. Not yet competent-Participants failed either in theory or practice or both of them.

Predictors of Competency were analyzed using logistic regression model. Model goodness of fit test was checked using Hosmer-Lemeshow statistics. All variables which were significant at a p-value of 0.05 in the binary logistic regression model were fitted into the multiple logistic regression models. Variables which were significant at a p-value of 0.05 in the final model were retained as independent predictors of competency among candidates.

\section{Results}

\subsection{Characteristics of Study Respondents}

A total of 287 participants were included in the study with a response rate of $100 \%$. The mean age of the respondents was $22.6 \pm 3.2$ years). Majority of study participants (57.8 percent) were Female. Regarding, residence higher proportion of the study participants (48.8 percent) were from Rural.

By religious affiliation a large majority of respondents (93 percent) were orthodox and Muslims accounted for 4.9 percent of study participants. By marital status composition about 212 (73.9 percent) were never married, and followed by married (22.3 percent).

Respondent's who took competency assessment one and two were about 73.5 and 13.9 percent respectively. The majority of the study participants' ownerships were governmental (86.4 percent). More than three-fourth of the study participants attend their schools with regular programs. Regarding the employment of the study participants, 22\%, 2.8\% and 75.2\% were employed, self employed and unemployed respectively. Regarding the purpose of competency taking by the study participants, 32\% and 56.8\% were for employment and further education respectively (Table 1 ).

\subsection{Knowledge and Attitude of the Participants towards Competency}

Among 287 candidates who were interviewed, 226 (78.7\%) were competent. The factors that were affecting competency, described by the candidates, were fear during assessment, examiner problem, and confidence of the candidates, preparation and academic background with a percentage of $54.4 \%, 46.6 \%, 46 \%, 23 \%$ and $20.6 \%$ respectively. The reasons mentioned to be not yet competent 58.2\%, 40.8\%, 39.7 and 27.2 were technical problem of the assessor; assessment questions were not representative, candidate's lack of preparation and low preparation for competency assessment by concerned bodies respectively.

About 204 (71.1\%) of the candidates believe that competency assessment is important for health professionals. More than three forth of the candidates know self-assessment guide. About 247 (86.1\%) candidates expected that their result will be Competent. Regarding the 92 (32.1\%) of the candidate told that the assistant of the college for the Competency assessment was excellent while 39 (13.6\%) of the candidates said that the college do not assist at all.

About three forth of the candidates know the unit of competency that they are going to take. About 162 (56.4\%) of the participants said that an individual has a right to complain if he had not examined fairly. With regard to the concerned body where a candidate complain 10.6\%, 9.9\%, $17.4 \%$ and 62.1 were said to college dean, committee designed for this, regional center of competency and supervisor respectively. 
Table 1. Socio demographic characteristics of the study participants, Debre Berhan Health Science College, $2013(\mathrm{n}=287)$.

\begin{tabular}{|c|c|c|c|}
\hline Variables & Categories & Frequency & $\%$ \\
\hline \multirow[t]{2}{*}{ Sex } & Male & 121 & 42.2 \\
\hline & Female & 166 & 57.8 \\
\hline \multirow[t]{2}{*}{ Age } & $18-24$ & 219 & 76.3 \\
\hline & $25-50$ & 68 & 23.7 \\
\hline \multirow[t]{3}{*}{ Residence } & Rural & 140 & 48.8 \\
\hline & Semi urban & 36 & 12.5 \\
\hline & Urban & 111 & 38.7 \\
\hline \multirow[t]{8}{*}{ Department } & Nurse level II & 82 & 28.6 \\
\hline & Nurse level IV & 3 & 1 \\
\hline & Pharmacy level II & 21 & 7.3 \\
\hline & Pharmacy level IV & 3 & 1 \\
\hline & Midwifery level IV & 55 & 19.2 \\
\hline & HIT level IV & 74 & 25.8 \\
\hline & Health extension III & 25 & 8.7 \\
\hline & Health extension IV & 24 & 8.4 \\
\hline \multirow[t]{3}{*}{ Religion } & Orthodox & 267 & 93 \\
\hline & Protestant & 6 & 2 \\
\hline & Muslim & 14 & 5 \\
\hline \multirow[t]{4}{*}{ Marital status } & Never married & 212 & 73.9 \\
\hline & Married & 64 & 22.3 \\
\hline & Cohabiting & 9 & 3.1 \\
\hline & Divorced & 2 & 0.7 \\
\hline Number of competency & One & 211 & 73.5 \\
\hline \multirow[t]{3}{*}{ Assessment } & Two & 40 & 13.9 \\
\hline & Three & 27 & 9.4 \\
\hline & Four and above & 9 & 3.2 \\
\hline Ownership of the training & Governmental & 248 & 86.4 \\
\hline Institute & Private & 39 & 13.6 \\
\hline \multirow[t]{3}{*}{ Training program } & Regular & 237 & 82.6 \\
\hline & Extension & 4 & 1.4 \\
\hline & Summer & 46 & 16 \\
\hline \multirow[t]{3}{*}{ Employment situation } & Employed & 63 & 22 \\
\hline & Self-employed & 8 & 2.8 \\
\hline & Unemployed & 216 & 75.3 \\
\hline \multirow[t]{4}{*}{ Purpose of the assessment } & Further education & 163 & 56.8 \\
\hline & Employment & 94 & 32.8 \\
\hline & Improving career & 15 & 5.2 \\
\hline & For nothing & 15 & 5.2 \\
\hline
\end{tabular}

About 157 (54.7\%) of the candidates have been ever faced/heard problem on competency assessment. Regarding from which side were the problems 53.5\%, 31.2\%, 19.7\%, 12.1\% and 7.6\% were on the assessor, on the way of assessment, on the assessment questions, on the supervisor and on the candidate respectively. Of the total participants 270 (94.1\%) satisfied with their profession (Table 2). 
Table 2. Knowledge and attitude of the participants towards competency, Debre Berhan Health Science College, 2013 (n = 287).

\begin{tabular}{|c|c|c|c|}
\hline Variables & Categories & Frequency & $\%$ \\
\hline Do you believe that COC & Yes & 204 & 71.1 \\
\hline \multirow[t]{2}{*}{ Is important for $\mathrm{H} / \mathrm{professionals}$} & No & 60 & 20.9 \\
\hline & I don't know & 23 & 8 \\
\hline How do you rate importance & Extremely important & 60 & 20.9 \\
\hline \multirow[t]{4}{*}{ of $\mathrm{COC} n=281$} & Very important & 80 & 27.9 \\
\hline & important & 79 & 27.5 \\
\hline & Not important & 32 & 11.1 \\
\hline & Not important at all & 36 & 12.6 \\
\hline \multirow[t]{2}{*}{ Do you know self assessment guide } & Yes & 217 & 75.6 \\
\hline & No & 70 & 24.4 \\
\hline \multirow[t]{2}{*}{ Have you briefed about self assessment guide } & Yes & 199 & 69.3 \\
\hline & No & 88 & 30.7 \\
\hline \multirow[t]{3}{*}{ Expectation of assessment results } & Competent & 247 & 86.1 \\
\hline & One of the two & 19 & 7.3 \\
\hline & I don’t know & 21 & 6.6 \\
\hline \multirow[t]{5}{*}{ Assistance of the College } & Excellent & 92 & 32.1 \\
\hline & Very good & 49 & 17.1 \\
\hline & Good & 94 & 32.8 \\
\hline & fair & 13 & 4.5 \\
\hline & Do not assist at all & 39 & 13.6 \\
\hline \multirow[t]{2}{*}{ Do you know unit of Competency } & Yes & 213 & 74.2 \\
\hline & No & 74 & 25.8 \\
\hline \multirow[t]{3}{*}{ Does an individual has right to complain } & Yes & 162 & 56.4 \\
\hline & No & 65 & 22.6 \\
\hline & I don't know & 60 & 21 \\
\hline \multirow[t]{4}{*}{ To whom did complain $n=161$} & College dean & 17 & 10.6 \\
\hline & Committee designed for this & 16 & 9.9 \\
\hline & Regional COC & 28 & 17.4 \\
\hline & Supervisor & 100 & 62.1 \\
\hline Ever heard/faced problem on & Yes & 157 & 54.7 \\
\hline Assessment & No & 130 & 45.3 \\
\hline \multirow[t]{2}{*}{ Satisfied with profession } & Yes & 270 & 94.1 \\
\hline & No & 17 & 5.9 \\
\hline \multirow[t]{2}{*}{ Result of the candidate } & Competent & 226 & 78.7 \\
\hline & Not yet competent & 61 & 21.3 \\
\hline
\end{tabular}

When the relationship of the study population to competency was examined, about 226 (78.7\%) of the study participants were male. Out of those who had been competent, $88.5 \%$ of the candidates were learned at governmental institution. Similarly when we saw the percentage of competency within the departments 72 (97.3\%), 23 (95.8\%), 64 (75.3\%), 35 (71.4\%) and 32 (58.2\%) were competent in HIT, pharmacy, Nursing Health extension and midwifery respectively. 


\subsection{Factors Associated Competency}

Four predictors namely department of the respondent, expectation of the results, number of competency taken and candidates' knowledge of their right and obligations emerged as independent predictors of competency assessment results from the logistic regression analysis. Logistic regression analysis showed that the odds of being competent increased when a candidate had no knowledge on their rights. The odds of being competent was three times higher among students who had no knowledge of their rights compared to those who had knowledge, AOR [95\%]; 3.7 [1.3, 10.3].

The study showed the odds of being competent is lower by $95 \%$ among midwifery candidates than pharmacy, AOR [95\%]; 0.05 [0.01, 0.45]. Expectancy of the competency results was associated with competency, with lower odds of being competent among candidates whose result expectation of either competent or not competent (one of the two) than the candidates who expect competent, [AOR (95\% CI) $=0.13(0.02,0.85)$ ]. Similarly, the odds of being competent was statistically significantly lower by $89 \%$ among candidates who took assessment four and above than who took two times $[$ AOR $(95 \% \mathrm{CI})=0.11(0.01,0.88)]$ (Table 3).

\section{Discussion and Conclusions}

The proportion of competency among candidates is consistent with report released by the competency center [1]. However, the notion of comparability between competency center report and this study should be cautiously interpreted as it appears that the later study includes both level based and the previous assessment technique [1].

Table 3. Predictors of competency assessment in Debre Berhan Health College, 2013.

\begin{tabular}{|c|c|c|c|c|c|}
\hline Variables & Categories & Frequency & COR 95\% CI & AOR 95\% CI & P Value \\
\hline \multirow[t]{5}{*}{ Department } & Health Extension & 49 & $0.11(0.01-0.88)$ & $0.09(0.01-0.81)$ & 0.031 \\
\hline & HIT & 74 & $1.56(0.14-18.06)$ & 1.13 (0.09 - 13.69) & 0.922 \\
\hline & Midwifery & 55 & $0.06(0.01-0.48)$ & $0.05(0.01-0.45)$ & 0.008 \\
\hline & Nurse level & 85 & $0.13(0.02-1.04)$ & $0.10(0.01-0.90)$ & 0.04 \\
\hline & Pharmacy & 24 & 1 & 1 & \\
\hline \multirow{4}{*}{ Expectation of the result } & Competent & 247 & 1 & 1 & \\
\hline & I don’t know & 10 & $0.22(0.06-0.80)$ & $0.64(0.17-2.35)$ & 0.499 \\
\hline & No response & 12 & $0.16(0.05-0.64)$ & $0.26(0.04-1.60)$ & 0.145 \\
\hline & One of two & 18 & $0.78(0.25-2.48)$ & $0.13(0.02-0.85)$ & 0.034 \\
\hline \multirow[t]{5}{*}{ Assistance of the College } & Excellent & 92 & $2.2(0.94-4.92)$ & $0.25(0.06-1.08)$ & 0.063 \\
\hline & Very good & 49 & $6.3(1.87-21.21)$ & $0.248(0.059-1.045)$ & 0.057 \\
\hline & Good & 94 & $2.07(0.91-4.70)$ & $0.319(0.049-2.082)$ & 0.233 \\
\hline & Fair & 13 & $1.26(0.33-4.85)$ & $0.278(0.073-1.056)$ & 0.06 \\
\hline & Do not assist at all & 39 & 1 & 1 & \\
\hline \multirow{5}{*}{$\begin{array}{c}\text { Number of Competency } \\
\text { assessment took }\end{array}$} & Four and above & 9 & $0.14(0.03-0.74)$ & $0.11(0.014-0.88)$ & 0.037 \\
\hline & One & 211 & $0.43(0.15-1.28)$ & $0.18(0.042-0.77)$ & 0.021 \\
\hline & Three & 27 & $0.19(0.05-0.69)$ & $0.192(0.04-0.94)$ & 0.042 \\
\hline & Two & 40 & 1 & 1 & \\
\hline & I don't know & 12 & $0.159(0.048-0.529)$ & $0.212(0.041-1.099)$ & 0.065 \\
\hline \multirow[t]{3}{*}{$\begin{array}{l}\text { Belief that competency } \\
\text { assessment is important }\end{array}$} & No $=2$ & 72 & $0.72(0.38-1.38)$ & $1.49(0.65-3.46)$ & 0.345 \\
\hline & Yes $=1$ & 203 & 1 & 1 & \\
\hline & I don’t Know & 60 & $0.98(0.49-0.95)$ & $1.86(0.79-4.35)$ & 0.151 \\
\hline \multirow[t]{2}{*}{$\begin{array}{c}\text { Candidates knowledge of } \\
\text { their rights }\end{array}$} & No $=2$ & 65 & $3.22(1.29-8.03)$ & $3.70(1.33-10.28)$ & 0.012 \\
\hline & Yes $=1$ & 162 & 1 & & \\
\hline
\end{tabular}


Cognizant of the potential effect on the validity of the study pertaining to the nature of the study objective, data were collected using interview and in-depth interview. This attempt however might result in social desirability bias. The scope of our study (limited to Debre Birhan Health Science College) limits its generalizability to other colleges and departments.

The study demonstrated that significant numbers of candidates were not yet competent in competency assessment and this may be due department of the respondent, expectation of the results, number of competency taken and candidates' knowledge of their right and obligations. Thus effective measures that consider the identified predictors could help alleviate the problem. This study recommends that undoubtedly arrange sound awareness creation schemes so as to scale up the positive attitudes of the candidates towards the system, trainers should be acquainted highly with the new modular system to deliver training. There is also a need to conduct more rigorous study that addresses the limitation and recommendations of this study as well.

\section{Acknowledgements}

We would like to extend our deepest gratitude to the Debre Berehan health science college for assisting this research. Our appreciation also goes to the staff of Debre Berhan health Science College and all the study participants for facilitating the data collection process. Our thanks are also extended to Tsgie Taye and Melese Getachew for offering computer services and for assisting in data collection process.

\section{References}

[1] Competency Assessment Center (2006) 2005 COC Summary Result. Baher Dar.

[2] Anitha, N. and Thenmozhi (2011) Interdisciplinary Journal of Contemporary Research in Business. Institute of Interdisciplinary Business Research, 3, 784.

[3] Leigh, I.W.S., Leon, I., Bebeau, Muriel, J., Lichtenberg, James, W., Nelson and Paul, D. (2007) Professional Psychology: Research and Practice. American Psychological Association, 38, 463-473.

[4] Shippman, J.S., Ash, R.A., Carr, L., Hesketh, B., Pearlman, K., Battista, M., Eyde, L.D., Kehoe, J., Prien, E.P. and Sanchez (2000) The Practice of Competency Modeling. Personnel Psychology, 53, 703-740. http://dx.doi.org/10.1111/j.1744-6570.2000.tb00220.x

[5] (1995) United States Office of Personnel Management, Assessment Decision Guide. http://apps.opm.gov/ADT/ContentFiles/AssessmentDecisionGuide071807.pdf

[6] Houston, W. and Robert, E. (1974) Multi-State Consortium on Performance-Based Teacher Education. American Association of Colleges for Teacher Education, 273.

[7] Taylor, P.J., Pajo, K. and Cheung, G.W. (2004) String Field. Dimensionality and Validity of a Structured Telephone Reference Check Procedure. Personnel Psychology, 57, 745-772. http://dx.doi.org/10.1111/j.1744-6570.2004.00006.x 